\title{
LA MATERNIDAD EN LA RED: EL CASO DE LAS MADRES SOLTERAS POR ELECCIÓN
}

\author{
BEATRIZ MONCÓ \\ Universidad Complutense de Madrid
}

Recibido: 19/05/2009

Aceptado: 19/06/2009

\section{Introducción}

A principios del año 2008 se inició $^{1}$ el trabajo de campo correspondiente a una investigación con el título genérico de: «Madres solteras por elección: proyectos familiares y políticas públicas», cuyo objetivo principal fue indagar en los múltiples aspectos que presenta un fenómeno, el de la monoparentalidad por elección, que ha sido poco estudiado en nuestro país. El caso de las Madres Solteras por Elección (desde ahora MSPEs) es, sin embargo, un fenómeno creciente que está teniendo cada vez más presencia en los medios de comunicación y en las noticias de la Red, especialmente en las páginas de los periódicos digitales y en las de instituciones especializadas de diversos tipos.

La investigación, centrada en la Comunidad de Madrid, tiene carácter cualitativo. Su base empírica consta, por ahora, de una muestra de 49 entrevistas (cuarenta y seis a mujeres y tres a varones, incluidos con el objetivo de un posterior análisis comparativo), de las que 35 corresponden a adoptantes y el resto, excepto dos ${ }^{2}$, a mujeres que han utilizado las diferentes Técnicas de Reproducción Asistida (desde ahora TRA) para ser madres. En esta investigación

1. El Equipo de investigación está compuesto, aparte de por la autora de este texto, por María Isabel Jociles, Ana María Rivas y Fernando Villaamil, así como por Pablo Díaz como colaborador. Se consiguió apoyo económico en la convocatoria Santander/Complutense para proyectos de investigación durante los años 2008 y 2009.

2. Estas mujeres son madres biológicas también pero por relaciones sexuales consensuadas con una persona de su entorno. En sus términos, son madres por «donantes conocidos» frente a los «donantes anónimos» propios de las TRA.

Feminismo/s 14, diciembre 2009, pp. 123-142 
etnográfica, además, se han recogido datos mediante observación sistemática en diversos foros de Internet creados por y para ellas, tal y como se comentará posteriormente, en aras al análisis discursivo. Los propios foros han sido una fuente importante para acceder a informantes y han iniciado, junto a los conocimientos personales del grupo de investigación, un sistema de «bola de nieve» que ha servido para la consecución del número final de entrevistadas. Finalmente, y además de consultar bibliografía especializada, se ha recopilado información documental derivada de distintas fuentes, como, por ejemplo, manuales de evaluación de la idoneidad y guías de información para la adopción, así como otros textos incluidos en diferentes webs o blogs dedicados a la monoparentalidad y a la adopción internacional. En este nivel metodológico, y, sobre todo, porque esa es su autodefinición, creo importante señalar que, cuando hablo de MSPEs, lo estoy haciendo de mujeres solteras que han deseado ser madre sin pareja, es decir, estamos ante proyectos personales que comienzan sin otra persona, en solitario, situando fuera de la muestra y del concepto de MSPE que aquí utilizo a aquellas otras mujeres que, aún pudiendo ser solteras y monoparentales, quedaron sin pareja con posterioridad al embarazo o la adopción, ya fuera por abandono, separación, divorcio o muerte.

\section{Las madres solteras por elección}

De acuerdo a las mujeres consultadas, podríamos hablar de un perfil de MSPE común, en principio, a las madres adoptantes y por TRA. Un perfil que se define, sociodemográficamente, constatando que estamos ante mujeres nacidas desde finales de los años sesenta a mediados de los años setenta a pesar de que algunas, el grupo de más edad, nacieron a finales de la década de los cincuenta. Todas ellas pertenecen a una clase media, son personas con estudios medios o superiores y tienen un trabajo que, en principio, les permite poder criar a un hijo en solitario. Desde una perspectiva sociocultural, estaríamos ante mujeres que han cumplido lo que socialmente se esperaba de ellas y de la generación a la que corresponden, es decir, chicas dedicadas primero a sus estudios y luego a sus proyectos laborales, que, mayoritariamente, han tenido e incluso han convivido con parejas, que han estado en muchas ocasiones deseosas de ser madres, pero que han dado una prioridad clara a cada logro en sus proyectos vitales; de ahí, precisamente, que se encuentren en un momento de sus vidas en que, por edad sobre todo ${ }^{3}$, deban poner en marcha su proyecto sin dilación:

3. La edad es la causa principal para decidir el momento preciso de tener un hijo solas. Evidentemente, existe una edad fértil en la que la reproducción es más sencilla y cuyo final 
Todo coincidió, que tuve esa ruptura (con la pareja), pero yo tenía claro que iba a tener un niño, entonces tenía 32 años, acababa de sacar la oposición, tenía un trabajo seguro, un sueldo bien, bueno bien, para lo que había ganado trabajando en dos sitios, corriendo de un lado para otro y tal. Entonces dije, esta situación es la ideal, soy joven, me da lo mismo si aparece alguien o que no aparezca y como esos procesos son tan largos a lo mejor acabo cuando tengo 40 años (Geli, madre adoptiva, 36 años) ${ }^{4}$.

Tuve una pareja durante nueve años, viviendo juntos seis. Él no quería tener hijos y yo sí. También es verdad que cuando los dos empezamos yo era muy pequeña ¿sabes? empezamos cuando yo tenía veinte años... Entonces como a los treinta años... no, todavía no había cumplido treinta nos separamos. Y aparte de otra serie de factores que siempre influyen en las separaciones, pero para mí era uno de los fundamentales. Sí, sí, porque yo siempre he tenido... es más, me hubiera apetecido tener más hijos...Y entonces, luego ya decidí. Bueno, yo tenía una vida así, como bastante de hacer cosas ¿no?...Yo tenía treinta y cinco años en ese momento y decidí que bueno, pues que ya me iba a poner... (Miriam, madre por TRA, 45 años).

Independientemente de que estas mujeres se vean o no legitimadas en la conducta elegida para ser madres ${ }^{5}$, e independientemente también de las diferencias que ven ellas mismas entre las vías de maternidad elegida, interesa recalcar que todas ellas son mujeres maduras, independientes económicamente, $y$, ciertamente, empoderadas, aunque ni en el mismo grado (en tanto que la conciencia de sí mismas y su poder es muy diverso) ni en todas las facetas de su vida, lo que constituye una paradoja interesante. En realidad, están más empoderadas como mujeres que como madres, precisamente porque ellas mismas, al compararse con las familias biparentales, se encuentran en inferioridad de condiciones. En este proceso de idealización social de la familia biparental que estas mujeres asumen, se inscribe también el hecho de que,

las MSPE por TRA suelen situar en torno a los 35 años. En el caso de madres adoptantes, la edad es importante para iniciar el proceso adoptivo en tanto que los tramos de edad de los niños están en relación al de sus madres; de manera que si alguien quiere un bebé o niño pequeño (de 0 a 3 años) tiene que comenzar pronto el proceso. No obstante esa regla general, cada país de adopción tiene sus propias normas.

4. A fin de respetar al máximo el anonimato de las informantes, todos los nombres propios que aparecen en el texto son ficticios. A pesar de haber hecho observación y seguimientos de foros desde que se inició el trabajo de campo, tal y como se ha mencionado, este tipo de citas corresponden a entrevistas en profundidad. Por otra parte, el objetivo de este texto es ahondar en su interpretación de la funcionalidad de la Red para su situación concreta, y no tanto en lo que ellas escriben o comunican a través de la misma que será objeto de estudio con posterioridad.

5. No es el objetivo de este texto pero, no obstante, quiero hacer constar que las MSPE tienen algunos problemas para encajar socialmente su maternidad, puesto que la legitimidad legal y personal que encuentran en su decisión no la ven reflejada, en ocasiones, en la sociedad que las rodea.

Feminismo/s 14, diciembre 2009, pp. 123-142 
en la inmensa mayoría de MSPEs, encontramos una continua alusión a las parejas y al futuro; es decir, no lo consideran esencial en sus vidas pero dejan muy claro que ninguna está a priori cerrada a la vida en común. Su elección de un hijo sin padre vendría dada más por su deseo de maternidad que por un rechazo al matrimonio o a la convivencia con una pareja; alguna, incluso, es más taxativa al respecto:

Si no es el cien por cien, el noventa y mucho, o el ochenta y mucho por cien de las personas que son monoparentales con hijos no han elegido desde el principio ser monoparentales con hijos, simplemente que como no encuentran la pareja o el padre o lo que sea, pues optas por ese camino, pero yo creo que, vamos, yo no conozco a nadie que su primera opción sea ser monoparental, o sea, tener hijos sin padre (Aurora, madre adoptiva, 50 años).

A pesar de estas ambigüedades, lo que podríamos llamar en general atributos ${ }^{6}$ de las MSPEs les hace ser un grupo de características muy marcadas. Por otra parte, y como no podía ser menos, parte de ese empoderamiento se ve generado, amparado y reforzado por el conocimiento y el uso de las Nuevas Tecnologías, tal y como veremos a continuación.

\section{Las nuevas tecnologías y las MSPEs}

El carácter patriarcal de la ciencia occidental y, por tanto, la no neutralidad de la tecnología y sus derivados ha sido un tema largamente tratado por las teóricas feministas a partir de los años 70. Se han necesitado años, investigaciones y una importante literatura ${ }^{7}$, no sólo para reivindicar el lugar que corresponde a las mujeres en el ámbito científico, sino para finalizar con la idea, tan esencialista por otra parte, que une, inexorablemente, a las mujeres y a la tecnofobia.

Internet se ha convertido en una plataforma universal en la que las mujeres tienen cada vez más presencia y protagonismo, a la vez que es un medio para integrar experiencias, opiniones e incluso ideología feminista y acción política. Webs como singenerodedudas.es, feminismoantelacrisis.es, ciudaddemujeres.com, e-leusis.net, mujeresenred.net, lopersonalespolitico.com o nodo50.org, sin contar páginas y direcciones de las diferentes instituciones del feminismo

6. Sigo a Bock, que incluye como comunes la edad, la responsabilidad, la madurez emocional y la capacidad fiscal (que en nuestro caso sería capacidad económica). Bock, Jane D. "Doing the Right Thing? Single Mothers by Choice and the Struggle for Legitimacy". Gender E Society, vol. 14, no 1 (2000), pp. 62-86.

7. HaraWAY, Donna. Ciencia, cyborgs y mujeres. La reinvención de la naturaleza. Madrid, Cátedra, 1996. Plant, Sadie. Ceros más unos. Barcelona, Destino, 1998. PÉrez Sedeño, Eulalia. «Las ligaduras de Ulises o la supuesta neutralidad valorativa de la ciencia y la tecnología». Arbor, nº 716 (2005), pp. 447-462. 
académico y/o político, dan buena muestra de un fenómeno imparable en el que las mujeres demuestran no estar reñidas con la tecnología más puntera. La Red, por otra parte, ha sido instrumento principal que ha permitido alcanzar diferentes interlocutores, variedad de vías informativas y un nuevo modo de expresión, creatividad y poder.

En este panorama es en el que quiero situar a los distintos foros y asociaciones en las que las MSPEs encuentran su lugar de reivindicación y discusión. Unos cauces que, como es habitual entre ellas, las unen unas veces y las separan otras, hasta el punto de que podríamos hablar de lugares propios de las MSPEs adoptantes y aquellos en los que se ubican las MSPEs por TRA. En el primer caso contaríamos con aquellos comunes a padres y madres adoptantes y en los que se aglutinan familias biparentales y monoparentales, por ejemplo, Adoptanepal o Adopcionafrica, y aquellos especiales para solteros y solteras como Adoptarsiendosoltero. En el segundo caso, destacaría la página de Masola (que también da entrada a las adoptantes) y, sobre todo, el foro por excelencia de las MSPEs por TRA que se denomina Madressolterasporelección ${ }^{8}$.

Las funciones de estos foros entran de pleno en las que cumplen las Nuevas Tecnologías: funciones informativas, de comunicación personal, de trabajo colaborativo, de intercambio de experiencias, como medio de expresión, como fuente de creatividad, como instrumento cognitivo, como instrumento de gestión, como medio de aprendizaje e incluso como medio lúdico? ${ }^{9}$ Pero considero que en el caso de las MSPEs estas Nuevas Tecnologías son además de vital importancia en tanto que cubren, inciden y fomentan un modo especial de estar y concebir una experiencia sumamente importante en sus vidas. Así pues, ¿qué obtienen las MSPEs de los foros y, por tanto, de la Red?

\subsection{Información y conocimiento}

Como decía anteriormente, es éste, quizás, el primer objetivo de las mujeres que se acercan a Internet antes de iniciar su proyecto de maternidad. Hay que

8. Referencias completas: <http://elistas.egrupos.net/lista/adoptanepal>; <http://es.groups. yahoo.com/ group/adopcionafrica/>; <http://es.groups.yahoo.com/group/adoptarsiendosoltero/>; <http://www.masola.org/>; <http://madremspe.multiply.com>, consultadas el 24-10-2009.

9. AREA, Manuel. Educar en la sociedad de la información. Bilbao, Declée de Brouwer, 2001; CASTELlS, Manuel. La era de la información. Economía, sociedad y cultura. Madrid, Alianza Editorial, 1997; DíAz, Capitolina. «La enseñanza de las TIC y la exclusión de las mujeres». Comunicación y pedagogía, no 148 (1997), pp. 16-20; JoYANES, Luis. Cibersociedad. Los retos sociales ante un nuevo mundo digital. Madrid, McGraw-Hill, 1997; LÉVY, Pierre. «Sobre la cibercultura». Revista de Occidente, no 206 (1998), pp.13- 31; SARTORI, Giovanni. Homo videns: La sociedad teledirigida. Madrid, Taurus, 1998.

Feminismo/s 14, diciembre 2009, pp. 123-142 
tener en cuenta, aquí, que el tiempo que separa la experiencia de unas y otras es vital para comprender su uso particular. Por ejemplo:

Entonces era el año 2001 y empecé a buscar, a buscar, y no encontraba nada, me fui a las hemerotecas, a los periódicos, empecé en Internet a buscar, también Internet... ha cambiado mucho, no se encontraba tanto, ponías en Internet «madres solteras» y solamente me salía lo de «Isadora Duncan ${ }^{10} \ldots$ Entonces empecé a buscar y tropecé con que la ley lo permitía aquí... Y cuando más o menos lo tenía claro empecé a buscar en qué sitios de España se podía hacer... Ahora ya estoy más informada y sé que prácticamente todas, excepto alguna por ahí, todas son clínicas serias, buenas y responsables en un 95\%. Pero también hay clínicas que venden semen por la Red (Rosaura, madre por TRA, 42 años).

La información que obtienen a través de Internet puede ser también importante a la hora de saber el proceso que debe seguirse con la presentación de la documentación preceptiva para adoptar o incluso con la normativa diferente que tienen unos y otros países:

Aquí la gente se lo está currando mucho, porque van colgando vídeos, hay gente que traduce. Yo porque lo leo todo, entonces sé que ellos están trayendo información, por ejemplo, estaban conectados con Francia como referencia ${ }^{11}$ y con Estados Unidos para saber... porque la gente se está currando mogollón esto... era un poco para saber los primeros niños y los aparatos de choque y luego decían: han cerrado tal orfanato y tal... (Gracia, en proceso de adopción, 41 años).

En realidad, lo que la informante está poniendo de relieve es cómo la Red permite una ruptura de fronteras por las que la información fluye de un modo incesante. Esta información, además, permite incluso una unión de las consumidoras ante lo que les puede resultar una discriminación o un problema. De ahí, también, que la información que se envía mediante los foros permita ir conociendo los entresijos de la administración por los que han de ir sus papeles e, incluso, el proyecto mismo de su inseminación o fertilización ${ }^{12}$ o la preparación de su propio cuerpo. De hecho, es normal encontrar en el foro

10. Isadora Duncan es una asociación de madres solteras de las que se distinguen las aquí referidas en tanto que, dicen, las primeras no tuvieron ocasión de elegir puesto que se quedaron embarazadas teniendo pareja, es decir el hijo en solitario no formó parte de un proyecto voluntario. He de indicar, no obstante, que algunas mujeres consideran electiva su decisión ya que solas continuaron con su embarazo.

11. La informante está hablando de la adopción de niños en Vietnam, país que se había abierto recientemente a la adopción internacional.

12. En nuestra muestra de mujeres que han utilizado TRA para quedarse embarazadas hay tanto las que han empleado inseminaciones espermáticas como las que han empleado Fertilización in Vitro. 
nombres de estimulantes ováricos como el Clonid o el Merapur, de hormonas como el estradiol, de pruebas como la salpingografía o la histerosalpingografía, o nombres que en ellas parecen comunes y habituales como folículo, blastocito, endometrio o miomectomía. Como indicaba anteriormente, la información se transforma así en conocimiento.

Y te van preguntando a antiguos de cosas nuevas. O sea, gente que entra nueva en el proceso la vas ayudando. (El foro) Lo utilicé mucho en el momento de la preasignación. Estuvimos usándolo ahí, con esta gente que también íbamos a ir juntos, eso lo usé bastante, correo y foro (Icíar, madre adoptiva, 44 años).

En el momento en que has pasado por reproducción asistida sabe perfectamente esa persona lo que le estás contando, y ya lo ha pasado. Y ya sabe ella y te entiende perfectamente. Por eso digo que el foro ayuda muchísimo, porque estamos pasando todas por lo mismo (Katy, en tratamiento por TRA, 36 años).

Este conocimiento implica, en ocasiones, que o bien las vías de acceso a la maternidad se modifiquen (por ejemplo, las penalidades que pasan algunas madres adoptivas respecto al tiempo de espera, la complicación de los trámites burocráticos, las condiciones sanitarias y físicas de los niños hacen optar por las TRA) o bien que, hecha la elección de la vía, se transforme todo el proceso:

Estoy justo en un cambio de proceso, porque con este médico he hecho ya dos inseminaciones pero paralelamente, a raíz de que entré en el foro...te vas enterando de cosas como el tema de la Seguridad Social. Claro, porque yo me metí directamente en una privada porque yo pensaba que en la Seguridad Social no te iban a hacer ni caso... Entonces, a raíz de eso que te digo, de que leí que las chicas del foro muchas lo habían intentado por la Seguridad Social, pues yo dije: mira, pues yo voy a intentarlo y entonces me derivaron a reproducción asistida, aquí, al hospital (Luisa, en tratamiento por TRA, 39 años).

En estos foros, la información que puede dar lugar al conocimiento procede siempre de otras personas que han tenido con anterioridad ese tipo de experiencia, son personas que saben más y enseñan a aquellas novatas que están empezando un proceso para ellas ya conocido. En realidad, tal y como ocurre generalmente con los espacios de mujeres en la Red, hay una ausencia de líderes puesto que estamos ante redes horizontales, difusas y flexibles, aunque, en este caso, sí se puede reconocer una presencia continuada de unos miembros que son los que mantienen las discusiones del foro. Dice una informante:

Una me contestó una cosa como de chiste, vamos, no de chiste, todo es mojarse. Yo sé que lo hizo con toda su buena fe, pero hizo una valoración... bueno, ¡no te puedes ni imaginar!...Pero es que como todos tienen ganas de expresarse, que me parece fantástico, pero yo no me considero ni capacitada,

Feminismo/s 14, diciembre 2009, pp. 123-142 
ni quiero entrar... jes que hay de todo! y además de que hay mil ochocientos miembros, pero participan treinta. Sólo es que entran los mismos, los mismos, los mismos, los mismos. Exactamente. Los demás los deben usar como yo: leemos, de pronto hay un tema que nos interesa y preguntamos (Carolina, en proceso de adopción, 37 años).

Esta mayor participación, que por parte de algunos puede ser considerada un acaparamiento del espacio del foro, puede ser interpretado como un interés especial para que funcione, dando lugar a que unas mujeres se consideren «del foro» mientras que otras simplemente lo utilizan de vez en cuando:

Yo las estoy empezando a conocer... que conmigo han sido encantadoras, claro, yo como además las conocí a través de Teresa ${ }^{13} . .$. entonces entré por una vía un poco, digamos más... Claro, y entonces, Vanesa me decía: «eres de las personas de confianza». Claro, entonces me llegó al alma, y digo ¿confianza? ¿y eso por qué? Pero, bueno, también como yo escribo mucho y estoy ahí como muy pesada con todas... También es cierto que cuando la mamá tiene el hijo se tiende a participar menos porque tienes menos tiempo. Una vez que ha nacido, la gente participa menos porque hay menos tiempo. Las que estamos más activas es las que estamos dentro del proceso de reproducción. Luego con el embarazo también la gente se relaja un poco ¿no? Luego las animadoras ${ }^{14}$ nos animan mucho a que sigamos ino? y demás. Creo que deben hacerlo (Katy, en tratamiento de TRA, 36 años).

Las opiniones de Katy nos sirven para ver dos cuestiones importantes: la primera, que su presencia en el foro es fiel reflejo de su proceso y que, por tanto, dependiendo de ciertas condiciones (tiempo, haber logrado el principal objetivo, deseos de permanencia), se continúa o no en él o se mantiene una presencia más o menos activa. Por otra parte, aun sin hablar de líderes, sí deja constancia de un grupo más especial que se conoce más, se implica en mayor grado y del que, en ocasiones, se destaca alguna otra persona por poseer características que a las demás les parecen muy positivas. Este es el caso, por ejemplo, de «Mamá Feliz», una mujer que se ha convertido en un referente especial para las participantes en el foro no sólo por sus comentarios o trabajo en el mismo sino también por su propia experiencia:

Después hay muchas cosas que voy (a tener) que ir resolviendo un poquito antes de que ocurran ¿no?, pero paso a paso. Eso además lo explicaron en el foro el otro día, porque Mamá Feliz sacó un tema de preguntas que te preocupan para el futuro... (Pregunta: Cómo explicar a tu futuro hijo lo de no tener padre) En eso me ha ayudado mucho el foro, porque empecé leyéndolo y vas leyendo cosas, vas leyendo cosas e incluso yo, hasta cierto punto no me lo

13. Se refiere a una amiga que a su vez conoce a las administradoras del foro. El nombre, como siempre, es un seudónimo.

14. Se refiere a las administradoras del foro. 
había planteado hasta que empecé a leer en lo del foro... Pues entonces desde pequeñito, pues inventarte un cuento... Hay un cuento muy bonito que lo escribió Mamá Feliz, que le explica a su hijo...Yo creo que Mamá Feliz fue una de las... es una de las administradoras, de las fundadoras. Y ella tiene ya un niño, que llama su pollito, de ocho años... Claro, es que ella tiene mucha experiencia. Y se toma muy en serio el foro... Sí, sí, además dice unas cosas preciosas, también. Escribe unas cosas muy bonitas (Katy, en tratamiento de TRA, 36 años).

Es interesante comprobar cómo el foro no sólo ofrece información de la que se puede aprender y que se puede transformar en conocimiento, sino que el foro mismo es el agente que configura las preguntas que son adecuadas al tiempo que, lo que denomino una mujer de respeto, ofrece las respuestas pertinentes. Sin lugar a dudas, en este caso sí hay una élite, un núcleo de mujeres, del que puede hasta destacarse una, que, por diversas causas, se han convertido en la guía y el espejo donde se miran las demás. Salvando las distancias teóricas, no puedo dejar de pensar en la sororidad y el affidamento tan propio de algunas comunidades femeninas.

\subsection{Los temas del foro}

Como es lógico, según el tipo de foro del que hablemos, podremos observar una serie de características diferenciales en los temas a tratar. Así, mientras que en los de adopción encontramos una centralidad en los problemas de trámites burocráticos, discriminación de las adoptantes monoparentales en algunos países, de apertura o cierre de los procesos adoptivos, etc.; en los de las MSPEs por TRA, los hilos de debate son una imagen clara del mismo proceso de fertilización al que se someten, primero, y a la experiencia de la maternidad y la crianza, después. Así, por ejemplo, si analizamos el de Madres solteras por elección, podemos hacer un recorrido por las «Pruebas médicas», la «Inseminación» o bien la «Fertilización in Vitro»; en caso de necesidad, podemos ver el proceso de «Ovodonación» y luego, una vez conseguido el «Embarazo», nuestra ruta seguiría hacia el «Parto» e incluso a «Mellizos y más». Una cita nos ayudará a entender el uso y la navegación por este proceso:

Lo utilizas (el foro) de muchas maneras. Como los mensajes están guardados mucho tiempo hay mucha información. Pero yo estoy metida en el foro desde abril, vamos, o en marzo, más o menos. Y lo vas mirando... bueno, lees muchas historias, te ayuda mucho. Y luego pues abres tu propio hilo, y das tu información, contestas...Vas entrando, poco a poco... la gente la verdad es que te informa de mucho ¿no? Por ejemplo, cuando me estaba haciendo la prueba de las hormonas, pues vas mirando mensajes, entonces vas viendo y la gente cuelga sus análisis ¿no? «La Eli se ha hecho la ecografía». Entonces, vas leyendo, entonces, vas aprendiendo. (Pregunta: $i$ y las cuestiones de

Feminismo/s 14, diciembre 2009, pp. 123-142 
crianza de niños?). Todavía no he entrado, porque yo, hasta que realmente no tenga yo ya mi embarazo... Yo seguiré luego por partes, pues ya me meteré en embarazo... Entonces, según las fases en las que estoy... Si tengo que pasar a FIV, al otro canal, pues pasaré. O sea que vas un poco leyendo, poco a poco. Yo leo dos paneles: el de FIV y el de Inse, el de FIV, la de la in Vitro, y la de las inseminaciones. Porque claro, tampoco puedes abarcar mucho, entonces, vas mirando, o el de pruebas, por ejemplo... como luego además se guardan un montón de tiempo, pues vas dando marcha atrás y vas viendo gente que le ha pasado lo que a ti (Salomé, en proceso de TRA, 39 años).

Aparte de estas vías, existen otros canales de consulta donde se reseñan aquellos problemas que más comúnmente tiene este colectivo de MSPE, por ejemplo, «Familia marental», «¿Cómo le cuento? o «MSPE en prensa», así como sobre la misma asociación, los actos que organiza o las reuniones de quienes forman parte del foro y que familiarmente llaman «kedadas y salidas». El foro Masola suele incluir también entrevistas a especialistas o a personas con experiencias semejantes, informaciones médicas, o noticias de interés y un hilo, que personalmente no he visto en otros foros, sobre «maternidad subrogada» y «subrogación interina», dado que aún es ilegal en nuestro país.

\subsection{Los foros y las redes}

Uno de los aspectos más interesantes de Las Nuevas Tecnologías es la generación de redes sociales que han ido dando lugar a la creación de comunidades virtuales que están siendo últimamente de interés en los estudios de las ciencias sociales. Es evidente, sin embargo, que no siempre es homologable un foro, creado habitualmente bajo un aspecto concreto, a una red social como tuenti o facebook, por poner un ejemplo. Sin embargo, los foros que nos ocupan cumplen con algunas funciones que los constituyen como verdaderas redes sociales, en el tradicional sentido que tenía el término sociológico, al cumplir muchos de los objetivos de las redes familiares y amicales.

\subsubsection{Feminización de las redes y configuración de identidad}

Lógicamente, mientras los foros de adopción permiten la participación a hombres que quieran adoptar, el foro de Madres solteras por elección es un foro excluyente, no sólo de varones ${ }^{15}$ sino, incluso, de aquellas madres solteras a las que abandonó su pareja. Dice una de las entrevistadas:

15. No es que haya una prohibición expresa, de hecho en alguna ocasión ha escrito algún hombre, pero su presencia es meramente anecdótica. 
El foro en principio se creó para madres solteras por elección, o sea, mujeres que hemos buscado la maternidad, decididas, con tiempo, pensándolo, decididamente, que no nos ha dejado nadie, que hemos ido a por ello. Entonces, en principio, eso es básicamente por reproducción asistida. Lo que pasa es que como siempre, de toda la vida, pues existen algunas mujeres que sí que consiguen algún amigo o alguien que acostándose ocasionalmente con él, o durante varios meses, yendo el día de la ovulación y justamente a ello, lo consiguen...Y luego, ¿qué pasa?, que han empezado a entrar chicas, que si las había dejado alguien... ¡Pero no en nuestro foro! ¡Ese es el mundo de madres solteras que las han abandonado! ¡Es otro mundo! El nuestro es el de familias elegidas así, que son elegidas así por la circunstancias (Eulalia, madre por TRA, 40 años).

Como vemos, aparte de servir de autodefinición de unas madres solteras determinadas (quienes desearon tener a sus hijos solas) y de exclusión de otras (aquellas que fueron abandonadas por el padre de sus hijos), este foro es netamente femenino y hay un total rechazo a que los varones intervengan en él. Son madres por TRA y estas técnicas demuestran muy claramente que los hombres no son necesarios en el mundo de la reproducción. Una de las informantes que utiliza habitualmente el foro relata:

Yo creo que cada vez es más normal (tener hijos estando soltera). Sin embargo, por parte del hombre yo creo que todavía queda ese «es que no nos necesitan». A ver, yo creo que hay un factor de machismo ahí, de decir: «¡Pero bueno, y yo qué! Como hombre ya no soy necesario». Y yo creo que eso, un poco, asusta... Bueno, el foro está lleno de mujeres, cada vez más. Y esto es una tendencia, de aquí a diez años va a haber muchos niños de madres solas (Katy, en tratamiento por TRA, 36 años).

Es significativo que mientras la informante aglutina y aumenta cada vez más el grupo de madres solteras, separa de un modo evidente y taxativo lo que sería el hombre y el producto, así como si el semen fuese un derivado de laboratorio y no humano, lo que sin duda entra a formar parte de la construcción de un padre ausente (simplemente «el donante», según sus términos) en el que ahora no podemos detenernos.

Por otra parte, estos espacios son un escenario de expresividad femenina incluso en los foros de adopción en los que los varones pueden intervenir de un modo legítimo. Esta tendencia a lo que podríamos denominar autoría femenina en la Red es claramente apreciada por algunas informantes:

Para eso los foros están muy bien, la gente sabe mucho de trámites. Y pregunté, mandé una notita y pregunté si sabía alguien si para ampliar el rango de edad había que solicitarlo en la CAM o simplemente preguntárselo a la $\mathrm{ECAI}^{16}$; me contestaron veintisiete... Entonces me contestó una chica y me

16. Las ECAIs con las Entidades Colaboradoras en la Adopción Internacional.

Feminismo/s 14, diciembre 2009, pp. 123-142 
contestó a mí en un aparte... bueno, normalmente son mujeres las que escriben ¿eh? Si son pareja, normalmente son las mujeres las que escriben (Carolina, en proceso de adopción, 37 años).

Entre las usuarias de estos foros, por otra parte, se van creando unos vínculos que se hacen más estrechos cuando otras relaciones sociales son más débiles o precarias o, como es mayoritariamente el caso que analizamos, cuando una fuerte experiencia compartida da lugar al nacimiento de un sentimiento de identidad. Algunas veces, el grupo identitario se origina muy al inicio de esa experiencia común, por ejemplo, el viaje al país en el que se va a adoptar, y se mantiene luego mediante el contacto en la red:

(Se conocieron) en el aeropuerto. Habían llegado todos, yo fui la última y ya estaban todos allí, y yo me acerqué a un grupo y digo: "¿sois los que vais? Sí, somos». Pues ya está, así los conocí. (El contacto) es por correo electrónico. Oye, qué tal vais. Y no se qué. Y una foto. E incluso las fotos que nos mandaban, pues nos las compartíamos. Oye, mira que mona está Raquel. Oye, mira como está Ramón. Yo con nadie que no sea de mi grupo yo no he mandado fotos ni nada (Irina, madre adoptiva, 41 años).

Esa identidad, en algunas MSPEs, es seña exclusiva de un grupo de mujeres que, primero, tomaron la decisión de ser madres solteras y, después, de aquellas que comparten, día a día, un proceso y una experiencia común:

Yo conocí el foro a través de una amiga mía que su amiga es madre soltera por elección, ya tenía su niño, y fue una de las que El País hizo un reportaje... Yo me lo leí, me pareció muy interesante y vi la dirección, y me metí en Internet y dije: «¡Ah, un foro, a ver qué tal esto!» Bueno, ya lo haré, ya me meteré otro día. Y va pasando el tiempo, va pasando el tiempo... y en diciembre yo las conocí porque justo vinieron a Montealto. Quedan, se hacen kedadas entre las madres y entonces vinieron a Montealto como diez madres, algunas estaban embarazadas, otras con un montón de niños... las conocí, estuvimos ahí un rato con ellas hablando y demás y ahí quedó la cosa. Muy simpáticas y demás $¿$ no? Y a las dos o tres semanas... me metí en el foro. Y fue meterme en el foro y hasta hoy. Y estoy enganchadísima, absolutamente. Absolutamente adepta al foro. ¡A mis niñas que no me las toquen! ¡Y que estén todas bien! (Katy, en tratamiento por TRA, 36 años).

\subsubsection{Redes infantiles}

En las madres adoptantes, el problema más relevante es, junto con la adaptaciones de los niños, el lograr que sus hijos no se sientan discriminados por el hecho de ser adoptivos o por la etnia a la que pertenecen, un problema este, evidentemente, más relevante cuando los niños tienen otro color de piel o unos rasgos étnicos muy marcados, por ejemplo los adoptados en África y Oriente. Estas madres adoptivas pueden explicar la falta de un padre a sus 
hijos remontándose a los orígenes biológicos de los mismos, otra cosa diferente será cómo explicarles las razones que propiciaron que entrase en el colectivo de niños para adoptar, sobre todo cuando tienen familia directa. Sin embargo, para las madres por TRA el mayor problema, tal y como han dicho algunas informantes, es el de poder explicarles su propia reproducción y la ausencia de un padre social que viva con ellos y les acompañe habitualmente. Así pues, aunque por diferentes razones, unas y otras consideran que el unirse a otros niños con igual situación familiar puede ayudar a su adaptación y a su normalización. De ahí, que, en muchas ocasiones, estas redes femeninas absorban en sí mismas redes infantiles, o incluso se superpongan las unas a las otras, a fin de que sus hijos encuentren acomodo entre iguales. En este sentido las «kedadas» organizadas a través de los foros y la Red, son la ocasión idónea:

Una de las cosas...es que también el fomentar el contacto entre nosotras es también por los niños. Es crearles también un espacio donde vean que hay niños como ellos. Claro, que no solamente están en entornos donde lo más normal o común, de momento, es padres de parejas... Luego, cuando empiecen a pasar los años, empezarán los divorciados y los separados, pero bueno, de momento la mayoría están en parejas. Entonces, claro, al hacer kedadas con los niños le ofreces otro lugar donde...un espacio donde esos niños (Katy, en tratamiento por TRA, 36 años).

Yo salía lo normal, pero me encantaba quedarme en casa leyendo un libro, viendo una película y esas cosas. Pero ahora, con la niña, a raíz de meterme en Internet y en los foros, y conocer a otras en su situación y demás, pues al final estoy todo el día de pingo por ahí. Sí, muchísimo más... en el foro de solteros, por ejemplo, hacemos normalmente como mínimo un par de comidas al año... Desde el 2005 que fue a la primera que fui... no me he perdido ninguna (Francisca, madre adoptiva, 43 años).

\subsubsection{Redes solidarias}

Mediante las características que vengo ofreciendo parece claro que los foros y las redes que se forman ofrecen información, conocimiento y relaciones entre adultas y entre los niños que nos hablan de un entramado personal y social que no está exento de colaboración, cuidados, apoyo y solidaridad, entendiendo estos términos, además, tanto en un aspecto físico, como material y afectivo o moral. No es extraño que algunas informantes hablen así del foro Madres solteras por elección:

Sí que la gente se hace favores. O sea, alguien que se queda con el niño un día, y tal, nos vamos de vacaciones juntas e intentamos, pues eso, que los niños estén juntos. Se nos van uniendo mujeres a través del foro que les ha cambiado la vida saber que existimos, porque claro, lo fantaseaban pero no se

Feminismo/s 14, diciembre 2009, pp. 123-142 
atrevían, pensaban que iban a estar solas y de repente nos han encontrado. Y nada, muy contentas. (Eulalia, madre por TRA, 40 años)

Yo sé que el sábado que viene se reúnen para algo y me han pedido a mí que si me puedo quedar con los niños. Pero me lo dicen a mí en persona. Me dicen: ¿Te puedes quedar con los niños? Y digo: vale, sin ningún problema (Katy, en tratamiento por TRA, 36 años).

O bien, una relación de solidaridad con quienes en ese momento están teniendo muchos gastos; realmente es bastante habitual que en el foro aparezcan mensajes que, por ejemplo, ofrecen el resto de medicación que ya no necesitan y que saben que son productos de coste elevado para la mayor parte de estas mujeres que se están tratando en clínicas privadas. La misma informante anterior se beneficia de esa generosidad y la comenta como un punto más a añadir a su visión positiva del foro:

Le quedaba a una chica, me escribieron y me han dado la medicación para esta in vitro; parte de la medicación, la otra no. Y he quedado con ellas y demás. Luego volví a quedar el otro día con ella un ratín. Pero primero quedé con ellas, me dieron una muestra para que se la llevase a la ginecóloga para ver si me la podía poner o no, me dijeron que sí, y ya quedo con ella y ahí van tres más, una de ellas ya era madre (Katy, en tratamiento por TRA, 36 años).

A pesar de agradecer tales ayudas, quizás el conjunto de informantes valora en mayor medida el apoyo y la ayuda moral que encuentran en aquellas personas que han pasado por estos procesos o el hecho mismo de que ese compartir entre iguales disminuye la tensión que crea el proceso en sí:

Pueden cambiar un poco la ansiedad que vas teniendo con el paso del tiempo, por hablar con otras personas que se supone están en circunstancias similares... estás en unas circunstancias similares y te trasmiten lo que están pasando y, bueno, parece que te calmas un poco esa ansiedad por estar con otras personas en situación parecida (Estrella, en proceso de adopción, 48 años).

(encontré el foro) a través de Internet, sí, navegando por Google... De una manera casual. Y me ha venido muy bien, la verdad, el tener el apoyo. Como ahora mismo la página web se ha convertido en eso, en un apoyo para las mujeres que están en tratamiento. Y a mí me habría venido de perlas tenerlo. Sí, claro, porque fue mucho tiempo y jen el fondo estaba sola! Porque sí, tienes tus amigos, y cuentas, pero no es lo mismo que eso, que participarles a otras personas en tu situación, lo que estás viviendo. ¡Te entienden mucho mejor! (Carmina, madre por TRA, 46 años).

Es precisamente ese apoyo moral, esa compañía solidaria que las mujeres encuentran, lo que les hace ver al grupo como una comunidad moral, de iguales, que incluso se asemeja a la familia. De nuevo Katy es muy explícita:

Yo creo que el foro cumple una función fundamental de apoyo... Y que te sientes, es muy curioso, a mí no me había pasado nunca esto ¿no? De 
repente, ¡somos una familia! Es virtual, pero al mismo tiempo tiene su parte que deja de ser virtual ¿no? Entonces, el hecho de compartir tantas cosas, que compartimos todas ¿no?, desde el tratamiento hasta que queremos ser madres y hacerlo solas, tantas cosas que, claro, te hace sentir como si fuera una familia. Entonces, la verdad es que es muy agradable (Katy, en tratamiento por TRA, 36 años).

La informante, en realidad, acierta plenamente cuando ese compartir lo eleva de categoría y lo carga con aquellos imperativos ideológicos que para ella supone una familia. El foro, y sus mujeres, cubren así huecos de comprensión, de experiencia y también de soledad que sienten muchas veces. No sólo una soledad física, sino esa soledad moral, radical, que te aparta de todo y de todos; de ahí que alguna de ellas incluso realice diferencias interesantes:

Yo soy madre sola, sola. Digamos que yo tengo ahí una pequeña carencia que, bueno, que intento suplir, pero bueno, todavía lo estoy trabajando, y es el no tener familia, o sea, yo tengo poca familia y lejos... Entonces yo a veces encuentro diferencia, y la encuentro tanto con mi círculo de personas casadas como con mi círculo de personas sin pareja (Diana, madre por TRA, 38 años).

Es significativa la distinción que esta informante realiza: ni con unos ni con otros. Ella es diferente y es el estar, como decía mientras la entrevistaba, «sola, sola» lo que la distingue.

A pesar de todas estas características, no todo son ventajas en estos foros. Las informantes son conscientes de lo multifacética que es la Red y de los inconvenientes que se pueden plantear, incluso surgiendo de sus mismos beneficios. Así, por ejemplo, si la información, el conocimiento y el aprendizaje que conlleva es algo positivo, los límites son muy tenues y pueden volverse en contra de la usuaria, de ahí que algunas prefieren encontrarse en lo que comúnmente conocemos como bendita ignorancia:

Sí, porque ahora, por ejemplo, estoy muy metida en el tema de adopción, estoy muy metida en foros...y claro, cuando ves cosas que, yo cuando hice la idoneidad ${ }^{17}$, a mí es que ni se me pasó por la cabeza que nadie pudiera decirme que yo no era idónea. O sea, es que eso ¡ni se me ocurría que pudiera plantearse! Y yo creo que luego, de ver los casos que se han dado, hubiera ido con miedo y a lo mejor hubiera sido peor. Entonces, bueno, tampoco me arrepiento de no haber mirado más cosas en su momento (Francisca, madre adoptiva, 43 años).

17. La informante se refiere al Certificado de Idoneidad que debe tener la persona adoptante. Se otorga o no después de varios trámites con la asistente social, psicóloga, entrevistas, etc.

Feminismo/s 14, diciembre 2009, pp. 123-142 
Para otras informantes, el problema de los foros consiste en la propia naturaleza de la Red; de ahí que admitan información pero que no crean viables el resto de ventajas de las que hemos hablado:

Yo entro a mirar y tal, pero ¡estoy más harta de eso! A ver, yo lo he utilizado para desahogarme; cuando me he quedado con un berrinche o lo que sea he escrito, porque me gusta escribir, y bueno, pues no sé, a lo mejor haciendo público mi malestar, pues ya me quedo más tranquila. Y luego para informarme de cómo van los temas y tal, pero yo es que no creo mucho en Internet. O sea, Internet me parece una herramienta muy útil, pero es algo como muy ficticio. O sea, los lazos que se crean ahí no son reales (Alicia, en proceso de adopción, 47 años).

Me metí en un foro, es que lo de los foros me da un poquito de miedo, o sea, lo empleo ¿eh?, leo. Leo porque muchas veces tienen información muy importante, te enteras mucho...o sea, que están al día completamente...Y cuando me pongo a mirar los plazos en los foros, cada cinco minutos aparece la firma de una, cuenta cuando se lo dieron, no sé qué. Y además es absurdo, porque cada plazo es un mundo, depende de un montón de cosas... Hay algunas cosas que yo alucino. O sea, cogen unos piques y analizan... ¡esa prisa! ¡Están obsesionados en el foro! ¡Están totalmente obsesionados! Entonces se pican unos a otros, entonces una se pone a decir que lo importante es saber los orígenes de la madre... y que si la otra sabe... Eso me da un poco de miedo, quiero decir, que da lugar a que la gente se cree más películas... Lees los foros y es que todos parecen que están en posesión de la verdad absoluta. Y entonces, cuando a una pobre se le ocurre mostrar la más mínima debilidad en algún tipo de tema es como ¡Aaaaaah! ¡Todos a saco! Entonces, te lo digo, lo pueden saber, pero hay que verlo un poquito desde la distancia, no involucrarte mucho... (Carolina, en proceso de adopción, 37 años).

La disparidad de opiniones, los caracteres personales de cada cual, la diferencia de las normativas, el tiempo que dura el proceso y la tensión que se acumula hace, probablemente, que las mujeres de los foros de adopción sean más críticas con ellos que aquellas que van a ser madres biológicas. Es raro encontrar una crítica tan extensa y pormenorizada sobre el foro de Madres solteras por elección a pesar de que en algunos momentos tenga inconvenientes:

Hay momentos que prefieres que no te hablen mucho de ello, incluso a veces del foro. Yo he tenido un momento así, y creo que fue en la tercera. La tercera inseminación fue la que más, yo creo que estaba más cargada psicológicamente y las hormonas me estaban afectando más, y bueno, yo creo que fue un cúmulo de todo, que incluso dije: ¡uf! necesito apartarme del foro unos días y no quiero hablar de esto con nadie. Necesitas también un poco de distancia. Sólo me ha pasado una vez y fueron dos días (Katy, en tratamiento por TRA, 36 años).

Sus palabras son muy significativas. Por una parte advierten del coste personal que conlleva la decisión, de la necesidad de apartarse del tema o, como 
dicen otras informantes, de esperar con tranquilidad, sin estar encima del proceso de continuo. Pero, por otra, Katy lo vive como una deslealtad, como un abandono del grupo, de ahí que aclare que sólo ha sido momentánea. De hecho, las mujeres que hacen uso de este foro lo ven como algo más personal, algo más privado e íntimo que las madres adoptantes el que utilizan. Quizás la razón esté en que la maternidad por TRA implica el cuerpo mismo de las mujeres y como tal se vive desde una subjetividad diferente ${ }^{18}$, teniendo muy presente estas mujeres que es un proceso que controlan en mucha mayor medida que lo que puede controlarse un expediente de adopción.

\section{Conclusiones}

Además de los aspectos señalados al hilo de las citas etnográficas, me parece necesario constatar cómo estas mujeres ofrecen, desde un análisis de género, una imagen un tanto paradójica. Por una parte, representan el ideal de la mujer posmoderna: buena preparación de estudios, un trabajo que les hace autónomas e independientes y una carrera con un cierto éxito, todo ello logrado desde una ideología igualitaria que les preparó para el mundo obviando su sexo y los imperativos de género. Por otro, en sus vidas encuentran un hueco sin cubrir: el de la maternidad. Todas ellas, además, son conscientes de que al ser madres van a ver colmados sus deseos pero que, al tiempo, su vida va a transformarse de una forma clara, incluso algunas, en la preparación de su maternidad, se adaptan a cambios laborales que convienen más a sus hijos que a sus carreras profesionales. Por otra parte, las pocas veces que en sus discursos aparecen ciertas demandas o expresiones de corte feminista son de un modo anecdótico, dejando incluso algunas muy claro que determinada toma de posición respecto a las MSPEs no les gusta a las mujeres del foro por considerarlas, precisamente, muy feministas. Su centralidad personal en la maternidad recuerda, a veces, los planteamientos del feminismo cultural, o incluso los del feminismo de la diferencia y el ecofeminismo, en tanto que,

18. Aunque no es momento de plantear extensamente esta cuestión, sí quiero indicar que durante el proceso de tratamiento estas mujeres visibilizan su cuerpo al máximo, siendo así un cuerpo atendido, interiorizado, mirado y controlado; en los foros se cuentan cosas privadas que dudo que fueran objeto de conversaciones habituales con personas a las que no se conoce personalmente. Los conceptos de referencia corporal (o incluso médica) se hacen habituales y se comenta sobre menstruaciones, falta de las mismas, óvulos, folículos o trompas como de algo cotidiano. Su embarazo, real o no en ese momento, se confunde con su identidad. El concepto de «antropología encarnada» es muy interesante en este aspecto (ESTEBAN, Mari Luz. «Antropología encarnada. Antropología desde una misma». Papeles del CEIC. no 12 (2004), <http://www.ehu.es/CEIC/ papeles/12.pdf>, consultado el 22-10-2009).

Feminismo/s 14, diciembre 2009, pp. 123-142 
en ocasiones, realizan una interpretación de la maternidad totalmente naturalizada; unas, porque les es sencillo al hablar de maternidad biológica, otras, porque incluso comparan momentos del proceso de adopción con hitos del embarazo (certificado de idoneidad, por ejemplo, con primera ecografía). En otro sentido, hay que indicar que, en el caso de las madres por inseminación o fertilización in Vitro, no encontramos la menor duda sobre la legitimidad de prestarse a la manipulación corporal que las TRA suponen, de ahí que estén muy lejos de plantearse aspectos de las mismas que se han debatido desde los estudios de género y feministas ${ }^{19}$.

Es necesario apuntar, sin embargo, que tales posiciones feministas y las críticas que conllevan se realizan en abstracto pero teniendo en mente otro tipo de sujetos, generalmente mujeres con parejas. Parece claro que el colectivo de mujeres del que aquí se ha hablado pudiera ser distinto al otro, lo que nos llevaría a la necesidad de realizar estudios comparativos que todavía no se han hecho, pues si bien el cuerpo (y su consiguiente uso y manipulación) y la técnica son las mismas, y por tanto muchas de las críticas al respecto pudieran ser absolutamente válidas, debería tenerse en cuenta algunas diferencias respecto a las intenciones y objetivos, la voluntad, la legitimación, la justificación ideológica y cultural, la maternidad, la fertilidad o infertilidad, el poder, las desigualdades de género y la feminidad y sus imperativos. Hasta que tales estudios no se realicen tendremos que tener presente que su deseo es tener un hijo y a ello se dirigen con las mismas ganas y la misma voluntad que han empleado en otros proyectos de sus vidas. Una cosa es la conducta y el discurso de las informantes, otra la interpretación y análisis que hagamos de los mismos; una tercera es lo que nosotras mismas, como feministas y expertas en género, pensemos del fenómeno que estudiamos. Aquí, en este texto, han tomado la palabra unas mujeres que, por encima de todo y a pesar de los problemas que conlleva, han querido ser madres en solitario; un fenómeno que hasta ahora ha quedado lejos de la reflexión de género y feminista. Los foros e Internet, no me cabe duda, les ayudan a ello.

19. Es de sobra conocido en los estudios de género cómo la relación tecnología-género no se ha cuestionado de modo tan intenso y enérgico como en el campo de la reproducción humana en general. Consultar, por ejemplo: TUBERT, Silvia. Mujeres sin sombra. Maternidad y tecnología. Madrid, Siglo XXI, 1991; TABOADA, Leonor. «Reproducción asistida». En M. M. González, I. Jiménez y B. M. Morgado. Maternidad y paternidad, reflexiones desde el feminismo. Oviedo. Instituto Asturiano de la Mujer, 2007, pp. 7585; STOLCKE, Verena. «Las nuevas tecnologías reproductivas, la vieja paternidad». En C.Amorós, L. Benería, C. Delphy, H. Rose y V. Stolcke. Mujeres: ciencia y práctica política. Madrid, Universidad Complutense, 1987, pp.87-129. 


\section{Referencias bibliográficas}

AREA, Manuel. Educar en la sociedad de la información. Bilbao, Declée de Brouwer, 2001.

Bock, Jane D. «Doing the Rigth Thing? Single Mothers by Choice and the Struggle for Legitimacy». Gender \& Society, vol. 14, nº 1 (2000), pp. 62-86.

CASTELLS, Manuel. La era de la información. Economía, sociedad y cultura. Madrid, Alianza Editorial, 1997.

DíAZ, Capitolina. «La enseñanza de las TIC y la exclusión de las mujeres». Comunicación y pedagogía, no 148 (1997), pp. 16-20.

EstebAn, Mari Luz. «Antropología encarnada. Antropología desde una misma». Papeles del CEIC. $\mathrm{n}^{\circ} 12$ (2004), <http://www.ehu.es/CEIC/papeles/12.pdf>, consultado el 22-10-2009.

HARAWAY, Donna. Ciencia, cyborgs y mujeres. La reinvención de la naturaleza. Madrid, Cátedra, 1996.

JoYANES, Luis. Cibersociedad. Los retos sociales ante un nuevo mundo digital. Madrid, McGraw-Hill, 1997.

LÉVY, Pierre. «Sobre la cibercultura». Revista de Occidente, nº 206 (1998), pp. 13-31.

PÉREZ SEDEÑO, Eulalia. «Las ligaduras de Ulises o la supuesta neutralidad valorativa de la ciencia y la tecnología». Arbor, no 716 (2005), pp. 447-462.

Plant, Sadie. Ceros más unos. Barcelona, Destino, 1998.

SARTORI, Giovanni. Homo videns: La sociedad teledirigida. Madrid, Taurus, 1998.

STOLCKE, Verena. «Las nuevas tecnologías reproductivas, la vieja paternidad». En C. Amorós, L. Benería, C. Delphy, H. Rose y V. Stolcke. Mujeres: ciencia y práctica política. Madrid, Universidad Complutense, 1987, pp. 87-129.

TABOADA, Leonor. «Reproducción asistida». En M. M. González, I. Jiménez y B. M. Morgado. Maternidad y paternidad, reflexiones desde el feminismo. Oviedo. Instituto Asturiano de la Mujer, 2007, pp. 75-85.

TUBERT, Silvia. Mujeres sin sombra. Maternidad y tecnología. Madrid, Siglo XXI, 1991.

Feminismo/s 14, diciembre 2009, pp. 123-142 